\section{MS38-O2 Methods for extracting and combining information from different datasets of crystalline samples}

Rocco Caliandro ${ }^{1}$

1. CNR - Institute of Crystallography, Bari, Italy

email: rocco.caliandro@ic.cnr.it

Statistical methods can be applied for the analysis of multiple measurements to extract relevant information. Principal component analysis (PCA), for example, has been recently used for achieving chemical selectivity in the framework of the Modulated Enhanced Diffraction technique [1-2], to identify the time-dependence of structural changes and to classify samples according to their X-ray powder diffraction (XRPD) profiles [3]. Statistical methods can be as well applied for the joint analysis of measurements from different techniques. Recent examples concern the use of PCA for comparing information from XRPD and infrared spectroscopy [4], and of the covariance matrix to combine XRPD with mass-spectrometry and NMR measurements [5]. Such multivariate analysis methods have been recently implemented a computer program devoted to crystallographic applications [6]. The statistical methods used and their implementation will be described, and examples of their applications will be given.

\section{References}

[1] Caliandro R, Chernyshov D, Emerich H, Milanesio M, Palin L, Urakawa A, van Beek W, Viterbo D (2012). Patterson selectivity by modulation-enhanced diffraction. J. Appl. Cryst., 45, 458-470.

[2] M. Milanesio, L. Palin, D. Viterbo, R. Caliandro, A. Urakawa, W. van Beek and D. Chernyshov (2014) Chemical Selectivity in Diffraction by Statistical Analysis of in situ XRPD Data Acta Cryst., A 70, C1471.

[3] R. Caliandro, A. Libutti, B. D. Belviso, G. Chita, M. Monteleone (2014) Characterization of plant biomass derived black carbon (biochar) as soil amendment by $\mathrm{X}$-ray powder diffraction European Biomass Conference and Exhibition proceedings, ISBN 978-88-89407-52-3 pag. 951-957.

[4] R Caliandro, G Di Profio, O Nicolotti (2013) Multivariate analysis of quaternary carbamazepine-saccharin mixtures by X-ray diffraction and infrared spectroscopy J. Pharm. Biomed. Anal. 48-79, 269-279.

[5] A Rizzuti, R Caliandro, V Gallo, P Mastrorilli, G Chita, M Latronico (2013) A combined approach for characterization of fresh and brined vine leaves by X-ray powder diffraction, NMR spectroscopy and direct infusion High Resolution Mass Spectrometry Food Chemistry, 141, 1908-1915.

[6] R. Caliandro and D. B. Belviso (2014) RootProf: software for multivariate analysis of unidimensional profiles J. Appl. Cryst., 47, 1087-1096.

Keywords: Multivariate analysis, Covariance matrix, Chemical selectivity, Qualitative analysis.

\section{MS38-03 Solid State - Solutions to the Solution and vice versa \\ Dietmar Stalke ${ }^{1}$}

1. Georg-August-Universität Göttingen, Institut für Anorganische Chemie, Göttingen, Germany

email: dstalke@chemie.uni-goettingen.de

In his seminal case study on the relationships between solvation, aggregation and reactivity in organolithium chemistry Collum stated " $X$-ray crystallography provides little insight into the thermodynamics of aggregation and solvation." [i] This is right for most chemical substances as the crystal structure is commonly believed to represent the least soluble derivative in the pot and not necessarily the most abundant, let alone the most reactive species. Moreover, the least populated species might represent the eye of the needle in the equilibrium the whole reaction goes through anyway on the course towards the overall product. The talk will elucidate the interaction of X-ray structure analysis, spectroscopy and computational chemistry. We synthesised, crystallized and structurally characterized various thermolabile s-block organometallic aggregates and studied their behaviour in solution by 1/2-D heteronuclear NMR experiments[ii] and computational chemistry[iii] to start from firm ground and explore their constitution and behaviour in solution. Unequivocally in this canon of methods X-ray structure analysis plays a leading role but all can learn from another: There are more beasts in the pot than those giving the nicest single crystals.[iv]Without structural information it is impossible to get the intermediates.[v]Structural plausibility, i. e. information from the CCDC provides new insights into solution.[vi]

[i] D. B. Collum, Acc. Chem. Res. 1992, 25, 448-454. [ii] M. Granitzka, A.-C. Pöppler, E. K. Schwarze, D. Stern, T. Schulz, M. John, R. Herbst-Irmer, S. K. Pandey, D. Stalke, J. Am. Chem. Soc. 2012, 134, 1344-1351. [iii] J. Hey, D. M. Andrada, R. Michel, R. A. Mata, D. Stalke, Angew. Chem. 2013, 125, $10555-10559$; Angew. Chem. Int. Ed. 2013, 52, 10365 -10369. [iv] A.-C. Pöppler, M. Granitzka, R. Herbst-Irmer, Y.-S. Chen, B. B. Iversen, M. John, R. A. Mata, D. Stalke, Angew. Chem. 2014, 126, 13498-13503; Angew. Chem. Int. Ed. 2014, 53, 13282-13287. [v] T. Niklas, D. Stalke, M. John, Chem. Commun. 2015, 51, 1275-1277. [vi] R. Neufeld, D. Stalke, submitted.

Keywords: interaction of X-ray structure analysis, spectroscopy and computational chemistry 